\title{
ALTERNATIIVSEID ETÜMOLOOGIAID VII KAIL, PENDIMA, RAIDAMA, RUTTAMA JA (MUNA)TAEL
}

\author{
LEMBIT VABA
}

\begin{abstract}
Annotatsioon. Artiklis esitatakse uus või täpsustatud etümoloogiline tõlgendus sõnadele kail : kailu 'valge peaga veis', pendima : pendida 'pehkima, pehastama', raidama : rajata $\sim$ raidada 'rikkuma, raiskama', ruttama : rutata 'kiirustama, tõttama' ja (muna)tael : -taela 'munakollane'.
\end{abstract}

Võtmesõnad: etümoloogia, sõnalaenud, eesti keel, läänemeresoome keeled, balti keeled

kail : kailu 'valge peaga veis'

kail on Lääne-Saaremaalt Kihelkonnalt registreeritud murdesõna, mille tähendust selgitab EMS nii: ise must ja ’valge pec oo 'valge kail; 'ruske kail; musta kail; ‘seoke 'valge joon käib kailul, oo pöigeti joon.

Sel Saaremaa sõnal on ilmne etümoloogiline vaste soome murdekeeles, kus kaila ja selle arvukad tuletised märgivad esmajoones valgekirjut vms karva kodulooma (lehma, härga, hobust). Sõnapere levib SMSi andmeil soome keele edela- (Varsinais-Suomi) ja Häme murretes (Länsi- ja EteläSatakunta, Pohjois- ja Etelä-Häme): kailas 'vaaleanruskeasta, valkokylkisestä lehmästä', kaila 'vaaleanruskean, valkokylkisen lehmän nimenä', kailake '(eläimestä) kirjava', kailakka 'kirjava hevonen', kailanen 'kirjava lehmä', kailava 'kirjava, laikkuinen', kaileva 'hevosesta, lehmästä: laikkuinen, kirjava', kailio 'ruskean ja valkoisenkirjava härkä', kailo '(valkoisen) kirjava lehmä, härkä t. hevonen', kailokas 'kirjava', kailu '(valkoisen) kirjava lehmä, härkä t. hevonen', kailuva 'kirjava (hevosesta)'. Soome kõnekeeles võib kailava tähistada ka kirjut riiet (vt NYS 1). Aleksis Kivi leksikonis leidub liitsõna kailokylki 'kirjavakylkinen (elukasta)' (Saarimaa 1916: 70). 
Soome tüvevariantide kail-o, kail-o-kas toel võib väita, et ee kail : kailu tüvevokaal - $u$ osutab lms käändsõnaliitele - $o$ (liite kohta vt Hakulinen 1968: 143-145).

Andrus Saareste (1953: 36) on uurinud lääne-eesti ja soome (eriti edela)murrete ühissõnavara ning toonud mh esile ligi 90 sõna, mis on ühised üksnes Lääne-Eesti saarte murdekeelega. kail aga puudub sellest loendist, seda ei leia ka EKMSist, mida võiks seletada asjaoluga, et Saarestel puudus paguluses ligipääs okupeeritud Eesti murdekogudele. Läänemeresoome keelte etümoloogiasõnaraamatud ei käsitle selle sõnapere etümoloogiat. Joos. J. Mikkola (1902-1903: 27) on põgusalt peatunud nendel läänemeresoome keelte balti laenudel, millele leidub etümoloogiline vaste üksnes muinaspreisi keeles (sm kela 'pool, -i, rull', ee kõlad 'vöökudumisriist' mpr kelan, sm rl panu 'tuli' mpr panno [panu], sm hirvi 'põder', ee hirv 'Cervus elaphus; metskits' mpr sirwis), ja lisanud provisoorselt veel mõne kõrvutuse, sh sm kailu'valgelaiguline / weissfleckig' mpr gaylis 'valge / weiss'. Võrdlus on usutav ja jäänud tähelepanuta põhjendamatult.

Oletatav balti laenualus on *gaila- 'valge', vrd mpr gaylis 'valge' < bltLä *gailas 'valge' < 'särav', ieur arhetüüp tõenäoliselt *ghoilo- 'särav'; toponüümikaandmetele toetudes oletatakse apellatiivi gail-a- esinemist ka muinaspreisi keelele lähedase jatvingi keele leksikonis (Būga 1959: 100; 1961: 135, 144; Toporov 1979: 131-133 sub gaylis; Mažiulis 1988: 312-315 sub gaylis; Pokorny 1: 488-489 sub *gu hèi- 'hele, särav'). Sellesse balti sõnaperre kuulub leedu sookailunimetus gaĩlis $\sim$ gaĩle , mida Kazimieras Jaunius 19. saj lõpukümnendite paiku võrdles eesti Ledum palustre nimetusega (soo)kail (Jaunius 1972 [1879-1903]: 309). Seejärel on Raimo Raag (1984: 258-262) osutanud, et eesti taimenimetus kail ongi balti laen.

pendima : pendida 'pehkima, pehastama'

Kõnealuse verbi esitab EKSS murdesõnana. VMSi ja EKMSi (2: 1014 Mädanema; 3: 616 Riknema) järgi on pendima ning selle hääliku- ja tuletusvariandid tuntud Põhja-Eesti murdekeeles: P peńdima, S (V11 Pöi) pendama, penduma, Lüg JõeK pentima, JõeK pentuma, Jõh IisR pöndima, Kuu pöndümä, Sim pönduma, K pennastama, PJg pennata- 'kõdunema, pehastama, pehkima (puu, palk, puulehed), tohletama (kaalikad), kopitama 
(vili naprades, hein), mädanema, mädanema hakkama (kala, liha, surnukeha)'.

Eesti vanemas leksikograafias on kõnealuse verbi kohta sellised teated: Göseken 1660: 237 (vermuffelt / verschimblet) heu / pennastut, sumpitut (hallitut) hein; Vestring 1998 [1710-1730]: 176 Pendint Maggo Ein mufflich Geschmack Rev; Helle 1732: 156 pendind maggo ein muflich Geschmack; Hupel 1780: 239 pendind maggo mufliger Geschmack H.

Wiedemanni sõnaraamat $(1973$ [1893]: 799, 800) toob rikkaliku valiku tuletisi, sh selliseid, mida hilisema murdekogumise käigus ei ole enam registreeritud, samuti mõningaid tähendussisu selgendavaid kasutusnäiteid: penduma : penduda, peńdima : peńdida, pendama : pennata $\sim$ pendada $(\mathrm{O})$, pennatama $(\mathrm{P})$, pennastama $(\mathrm{F})$ 'mufflich werden, modern, stockig werden, moderig werden': wili läheb nabrus penduma 'das Getreide fängt an in den Schobern mufflich zu werden (bei anhaltend feuchtem Wetter)', laud pendub ära 'das Brett vermodert, fängt an zu faulen', nahk pendub 'die Haut wird wund', peńnitama, pennutama 'mufflich, moderig machen, zum Faulen bringen'.

pendima tuleb ette Friedrich Reinhold Kreutzwaldi keelekasutuses: pendimata [surnukeha] (1843, Sippelgas I: 41), pool pendinud [puulehed] (1861, Sippelgas II: 36$)$.

Toodud eesti verbidel on etümoloogilisi vasteid teadaolevalt üksnes soome murdekeeles: Kaakkois-Häme Kymenlaakso Keski-Suomi pentyä 'mennä pilalle kostuttuaan, tunkkaantua, homehtua, lahota (kangas, nahka, puu) / faulen, modern, morsch werden', Keski-Suomi pöntyä id., LänsiUusimaa penttautua 'lahota (esim. nuora)' (SKES 3: 521; SSA 2: 337). Eesti-soome verbitüve kõrvutus permi esinemusega (udm pedinini 'hapnikupuuduse tõttu jää all lämbuma (kalad), hingeldama; kopitama, läppuma', koS pędni 'hingeldama; uppuma') ei päde eelkõige häälikulistel põhjustel (KÈSK 1970: 227; SSA 2: 337, kus lisa asjaomasest kirjandusest).

Julius Mägiste osutab, et noomenitüvest *pentä on refleksiivliidetega $-i-<-\ddot{u}$ - ja $-u$ - tuletatud ee peńd-i-ma, pend-u-ma, tõenäoliselt kausatiivliitega $-a-<*_{-}(\ddot{a}) \delta \ddot{a}$ - pend-a-ma, neist omakorda liitega -sta- penna-sta-ma ja liitega -ta- penna-ta-ma, penni-ta-ma, pennu-ta-ma (EEW 6: 1988).

$\ddot{o}$-lised variandid (ee pöndima jt, sm pöntyä) ja oletatavasti siia kuuluv nasaalitu tüvevariant ee mrd pettima 'umbsuse tõttu pehastama, kõdunema' (EKMS 2: 1012 Mädanema; 3: 616 Riknema) kõnelevad ilmsest tunderõhutaotlusest. Ee pinnastama, pinnatama 'etwas faulen, so dass sich die 
Rinde löst' ja ponduma, pondutama (P) 'mufflich, moderig weden' on lähenenud ja segunenud verbidega pinna(s)tama 'pilbastama, killustama / splittern' (Wiedemann 1973 [1893]: 822, 846) resp. ponduma 'niiskuse tõttu paisuma, tursuma'.

Oletan, et kõnealune eesti-soome verbitüvi pentV- on balti laen, millele olen provisoorselt tähelepanu juhtinud juba varem (Vaba 1990: 134; 2015: 50): blt *pendV-: vrd ld péndèti (péndèja péndi, péndejo), pendéti, pendýti, pindèti (pìndi, pindèjo), pindéti 'lagunema, murenema, kõdunema, mädanema, roiskuma, kopitama; viletsaks, kehvaks, nõrgaks, otsa jääma, kiduma, ära, kokku kuivama', išpéndèti 'pehkima, kõdunema, mädanema (talumaja, puuoksad, kasvava puu südamik); kõvaks kuivama (liha); kõhnaks, lahjaks, viletsaks jääma, kuivetuma (haiguse, vanaduse tõttu), raugastuma' (LKŽ; oletatav ieur arhetüüp võib-olla *(s)pen- '(pingule) tõmbama', LEW 1: 569-570; Smoczyński SEJL sub péndèti; ALEW 2: 776-777 sub pintis, pintìs 'kuiv puukäsn, tael').

\section{raidama : rajata $\sim$ raidada 'rikkuma, raiskama'}

raidama $\sim$ raidema '(noort metsa) hävitama, raiskama' ja samatüveline, verbaalnoomenist raid lähtuv adverb raidu 'raisku' - raidu minema, raidus 'raisus' - on saarte ja läänemurde sõnad, kuid teateid on ka Harjumaalt (EKMS 1: 576 Hävitama; 2: 891 Metsandus; 3: 508-509 Raiskama; 4: 790 Äparduma; VMS). Nõrgaastmelisest tüvekujust lähtuvad MMg rajama 'raiskama (vilja niitmisel, lapsed leiba seda süües)' ja Hää rajastama 'raiskama (loomad rohtu seda tallates)' (EKMS 3: 509 Raiskama). Eeldades häälikulist ümberkujunemist kadjama 'joostes põgenema', kodjama 'ringi hulkuma' vms tüüpi verbide eeskujul või tavatut metateesi -aid->-adj-, võib sõnaperre kuuluda K radjama 'tallamisega hävitama või rikkuma': Kas sa tulid, kui su hobused mu kapsa ära radjasid? (EKMS 1: 576 Hävitama $<$ Tammsaare „Tõde ja õigus“ I).

Sõnapere kohta on teateid eesti vanemas kirjasõnas ja leksikograafias: Vestring 1998 [1710-1730]: 198 Raidama Verschwenden, ruiniren, verspillen, Raidawad pillowat Ölle Körret ärra. Sie verspillen nur das Stroh, Temma on raides. Es ist gantz zu nichte, Se on agga rahha rajos Das dient nur Geld zu verspillen; Helle 1732: 398 raido: pölletamast ka perre linnud sawad hukka, pu lähhäb raido 'durch Brennen kommen sonsten die guten Bienen um und der Stock geht zu nicht'; Hupel 1780: 253 raides zu nichte r., 
raido minnema zu nichte gehen r., raiduma ruiniren, verschwenden $\mathrm{r}$. Ka Wiedemanni sõnaraamatu (1973 [1893]: 921) näitestik on rikkalik, sisaldades mh juhte, mida hilisema murdekogumise käigus ei ole enam registreeritud: raidama $:$ raiata $\sim$ raidada '= raiskama': aega raidama 'die Zeit verschwenden, vertrödeln', raiduma : raiduda (SW) 'vernichten, ruiniren, verschwenden; (intr.) zu Grunde gehen', raid : raiu: raidu minema 'zu Grunde, zu nichte gehen', raius olema 'verdorben, dem Verderben Preis gegeben sein': se on aga raha raiuks 'das ist nur zur Geldverschwendung'.

Eesti sõnaperel ei ole usutavaid etümoloogilisi vasteid teistes läänemeresoome keeltes. ${ }^{1}$ Mägiste (EEW 8: 2392) oletab, et raidama on vahest hüpokoristilise värvinguga tuletis (,dürfte eine hypochor[istisch] gefärbte Abl[eitung] --- darstellen“) läänemeresoome sõnatüvest raja-: rajakas 'kalts, kaltsakas, närukael / Lumpen, Lump, Lumpenkerl', raiskama 'pillama, maha prassima / verschwenden, verprassen'. Mägiste seletus ei ole ei häälikuliselt ega semantiliselt veenev, kuigi raiskama-verbi mõju raidama-pere tähendusväljale on ilmne.

Oletan, et kõne all on balti laen, millele olen provisoorselt tähelepanu juhtinud juba varem (vt Vaba 1990: 134): blt *braidV-, vrd ld braidýti (braĩdo, braĩde), bráidyti 'sumama, sumpama, kahlama; tallama, sõtkuma': arklys braĩdo rugius 'hobune tallab rukist', braĩde 'hulkur' (> vlgvn бро́йдащьь '[vees kahlates] kala püüdma', брэ́йдащйа 'lonkima, luusima', Laučiūtė 1982: 63), nubraidýti 'maha tallama, sõtkuma (haned, loomad vilja); sumbates, kahlates väsima', apibraidýti '(jalge alla, segi) sõtkuma': šiąnakt arkliai gerokai apibraídè rugius 'täna öösel sõtkusid hobused kõvasti rukist'; ld braidyti on iteratiiv verbist bristi (breñda, brìdo) 'kahlama, sumama, sumpama / waten', vrd lt brist (bried brien, brida) id. (LEW I: 58 sub bristi; LEV 1: 146 sub brist (blt *brenda- > ee rändama : rännata 'liikuma, kulgema', sm rentiä 'kahlata, sumbata', is rännädä 'sebida, sekeldada', krjA räntätä 'rassida, kahlata, sumbata'); Smoczyński SEJL sub braidýti; ALEW 1: 128-129 sub bráidžioti 'kahlama, sumpama'; Pokorny 1: 164 sub *bhred(h?-) 'kahlama, sumpama'). Verbilaenu oletatav

\footnotetext{
1 Retsensendi arvates on eesti verbi etümoloogiline vaste vps raja-ta 'minema kihutada, välja ajada; sisse torgata, läbi torgata; pillata, raisata, läbi lüüa' (Zajceva, Mullonen 1972: 462), ent eelkõige häälikulistel põhjustel on see välistatud, sest vepsa keeles puudub astmevaheldus. Võimalik, et vepsa verbitüve etümoloogilised vasted on krjT rajata 'ära lõhkuda, rikkuda, ära vaevata, vintsutada, haiget teha', A rajattuo, rajavuo 'ära, kõlbmatuks kuluda' (KKS, vt ka SSA 3: sub raja²).
} 
algne tähendus on olnud 'maha tallates, sõtkudes (tallamisega) rikkuma ja hävitama', millest eesti keelekontekstis on hargnenud tähendusliin 'raiskama, pillama'.

Samast balti sõnaperest lähtuvad liivi ja eesti keele läti hilislaenud lvK brē'd'â, bre'd'd'ô, bred'ùs 'kahlata, kahlab' < 1t bried 'kahlab' (Kettunen 1938: 28b), eeLei prid'i 'sumas (lumes, poris)' < lt brida id., eeKhk pratutama 'kuhugi kiiresti minema; rabelema' < lt bradāt 'sumama, kahlama; (ära) tallama, (maha) sõtkuma, trampima', iteratiiv verbist brist (Vaba 1997: 166, 340).

\section{ruttama : rutata 'kiirustama, tõttama'}

ruttama ja samatüvelised rutt : rutu 'kiir,-u, tõtt, ruttamine': suur rutt taga, selle tööga on meil suur rutt, ruttu 'kiiresti, kähku, kärmesti' on hästi tuntud kogu eesti keelealal (EKSS; VMS; EKMS 3: 664: Rutt). ruttama, ruttu, samuti rutem 'kiirem, nobedam' kuuluvad tänapäeva eesti keeles 10000 sagedama sõna hulka (Kaalep, Muischnek 2002).

Eesti vanemas kirjasõnas ja leksikograafias noteeritakse järjekindalt vaadeldava sõnapere liikmeid: Müller 1600-1606: 302 ruttu kz ['rutu kaas, s.o rutuga']; Rossihnius 1632: 312 ruttutasit'(nad) ruttasid': nüd palju raghwast teine teise man olli, ninck neist lihnust temma mannu ruttutasit ---; Stahl 1637: 51 Plötzlich mit ungestüm eilen / ruttutama; Göseken 1660: 166 Eilen mit Ungestüm / Ruttoma, töttama, Eile / eilung / rutto / u, 211 geschind (adverb.) heckiselt / ruttust; Vestring 1998 [1710-1730]: 211 Rut G to Die Eyle, Ruttama / Ruttustama / Ruttuma Eilen, Ruttakas-Ma. Gut treibend Land ['ruttu kasvatav maa']; Helle 1732: 171 rut die Eil, das Eilen, ruttama, ruttustama eilen; Hupel 1780: 216 rut, to Eil, das Eilen r., ruttama, ruttustama, ruttuma eilen r. d. Hakkab küll silma, et Johannes Gutslaffi saksa-eesti sõnastikus on saksa sõna eilen vasteks rühkma, mitte ruttama (Gutslaff 1648: 211), kuid Rossihniuse keelekasutus peaks kinnitama, et ruttama ei ole siiski uudissõna tartu ja võru murdekeeles. Seda tõdemust toetab Inge Käsi „Vanapärase Võru murde sõnaraamatu“ näitestik (vt Käsi 2011: 631-632). Wiedemanni sõnaraamat (1973 [1893]: 988) esitab ruttama : rutata $\sim$ ruttada ja ruttuma : ruttuda 'eilen' kõrval mitu haruldast verbituletist: rutastama, rutustama, rututama 'Eile machen, antreiben', rutatelema $=$ ruttama, rutendama 'beschleunigen'. 
Mägiste järgi on tegemist läänemeresoome-lapi sõnatüvega *rutta-, mis on ruttama-verbi tuletusalus, rutt : rutu on arvatavasti $u$-liiteline $(<-o$ või ? $-u)$ verbaalnoomen. Eespool toodud verbide tuletusseoseid on Mägiste selgitanud nii: ruta-sta-ma, ruta-tele-ma on tuletatud verbitüvest $<$ rutta-, seevastu ruttu-ma, rutu-sta-ma, rutu-ta-ma noomenitüvest rutt : rutu, aga rute-nda-ma tuletusalus on komparatiivivorm rutem (EEW 8: 2562-2563).

Eesti sõnaperel on etümoloogilisi vasteid kõigis läänemeresoome keeltes, v.a liivi ja vepsa:

- vdj ruttaa $\sim$ ruttā $G:$ rutan 'rutata, kiirustada, (midagi) kiiresti või kiirustades teha / спешить, торопиться', ruttava 'kiire, kärme, vilgas / проворный', rutto 'rutt, kiirustamine; kiire, kärmas; pakiline, rutuline / поспешность, спех; быстрый, скорый, торопливый, поспешный; спешный, срочный' (VKS 5: 116-117);

- sm rutto 'äkisti tappava tauti; (I Pohjois-Suomi) nopea, ripeä; äkkipikainen', ruton, ruttoon 'yhtäkkiä, nopeasti', Laatokan Karjala Pohjois-Karjala Savo rutakka 'nopea, ripeä, rivakka; äksy, pikainen' (SKES 4: 887; SSA 3: 112-113); Ingeri elä ruta 'ära rutta' (? < ee Mägiste 1933: 372);

- is ruttā : ruDan 'kiirehtiä', ruttīssa 'kiirehtiä, pitää kiirettä', ruttō 'kiireesti', ruttoiza 'schnell', ruDottā 'kiirehtiä toista' (Nirvi 1971: 490, 493), rudada 'rutata' < ee (Laanest 1964: 31);

- krjViena (Kiestinki) rutoštoa 'kiirehtiä, hätäillä, hoppuilla', Raja-Karjala (Korpiselkä) rutostuo 'kiivastua, suutahtaa' (KKS); A rutostua 'midagi tuhinaga teha, kiirustada, rutata / делать чтол. с горячностью, спешить, торопиться', rutostuo 'ägestuda / начинать горячиться, загорячиться', rutto 'äkilise loomuga, keevaline / с крутым нравом, горячий', ruttoh 'ruttu, kiiresti, äkiliselt / быстро, круто' (Makarov 1990: 318); Viena Raja-Karjala A rutto 'hyvin nopea, pikainen, äkillinen, odottamaton t. yllättävä, äkki-, eloisa, vilkas; kiivas, äkkipikainen; altis, herkkä; jyrkkä, kiperä', A ruttovuo 'kiivastua, pikaistua', rutto surmu ['kiire, äkiline surm'] (KKS); T rutoštua, rutottua 'midagi kiiresti teha, kiirustada, rutata / быстро делать что-л., торопиться, спешить', rutto 'kiire, kärmas, äkiline, keevaline / быстрый, крутой, горячий', rutoldi 'äkiliselt, ruttu, kärmesti / круто, быстро, скоро' (Punžina 1994: 245); 
- lü ruttoi 'nopeasti, yhtäkkiä' (SKES 4: 887 sub rutto; SSA 3: 112 sub rutto).

Lapi vasted ei kuulu tõenäoliselt läänemeresoome-lapi ühissõnavarasse, nagu on oletanud Mägiste, samuti Alo Raun (1982: 146; seda seisukohta kordab ka ETY), vaid need on pigem vanemapoolsed läänemeresoome laenud: lpPite rohhtū 'kiire', Lule råhttō 'kiire; rutto', Põ rot'to 'rutto' (SKES 4: 887 sub rutto; SSA 3: 113 sub rutto).

Ebaõnnestunuks tuleb pidada katset osutada läänemeresoome sõnapere laenualuseks vene крутóú 'järsk, jääras (nt kallas, kurv); vali, karm, äkiline (nt iseloom); kõva, tihke, tihe, paks (nt kõva muna, paks puder)' ja кpýmo 'järsult, äkiliselt; valjult, karmilt; tugevasti, rohkesti, tihedalt' (vt EEW 8: 2563). Samas ei saa välistada siin nimetatud häälikukoostiselt sarnaste vene sõnade semantilist mõju (tähenduslaene) läänemeresoome sõnapere soome idamurrete ja karjala esinemusele, pidades silmas võimalikke laenulisi tähendusi 'ägedaloomuline, vihane', 'järsk, jääras', 'ägestuda, vihaseks saada'. Vahetud vene sõnalaenud on aga krjA jm kruto kruuto 'jyrkästi, runsaasti, rankasti; ankarasti' ja krutoi 'jyrkkä, rankka; ankara, kiivasluonteinen' (KKS).

Soome-karjala sõnas rutto 'katk, äkiline, kiire surm' on tahetud näha germaani laenu (Mikkola 1902-1903; Karsten 1915) ja kõrvutatud seda sõnadega gt prutsfill 'pidalitõbi', visl prute 'mädapõletik, paise' (SSA 3: 113), ehkki August Ahlqvist oli juba 1871 veenvalt osutanud tähendusarengule rutto-tauti 'kiire haigus' > rutto 'katk' (Ahlqvist 1871: 72 viide 2; vt ka Hakulinen 1968: 256).

Oletan, et kõnealune läänemeresoome sõnatüvi on balti laen, millele olen provisoorselt tähelepanu juhtinud juba varem (Vaba 1990: 135; 2015: 50), proponeerides laenualuse blt *kruta-, mida tänapäeva leedu keeles jätkavad nt

- ld krutéti (krùta, krutéjo) 'liikuma, end liigutama (elusolendi, seadme või selle osade kohta), siia-sinna liikuma; agarust üles näitama, kihama, sagima; värisema, vabisema, tuksuma, pulseerima; midagi tegema, töötama, kobestama (mulda), harima (maad), kaapima, puhastama (loomanahku); teele asuma, minema (käies, sõites); elama, asuma / sich bewegen, sich rühren' (> vlgvn кpýmau̧ 'liikuma, end liigutama / шевелиться', Laučiūtè 1982: 69); krutas 'liikumine, töö', krutùs 'elav, vilgas, liikuv, osav, töökas, toimekas', krùtinti 'liigutama, liikuma panema, taga sundima, ergutama, taga 
kihutama midagi tegema; teele asuma, rändama'; krùsti (kruñta, krùto) 'liikuma hakkama, kähku tegema hakkama, käsile võtma, kallale asuma': sukrusti pie darbo 'töö kallale asuma' (LKŽ);

- Itg krut'iêt' 'suutma, jaksama midagi teha, toimetada', krutavuôt' 'midagi kärmelt tegema, toimetama' (Rek̦ēna 1: 524);

- oletatav ieur arhetüüp *kreu-t- (*kreu-dh-?) 'raputama, keerutama, vilkalt liigutama' (LEW 1: 303; Smoczyński SEJL sub krutéti, krutùs; Pokorny 2: 623 sub *kreu-t- 'raputama, lehvitama, elavalt liigutama'; vrd ka ALEW 1: 531 sub krutéti, kus mh nimetatakse leedu verbi võimalikku laenamist idaslaavi keeltest: vn крути́mь, vlgvn круuฺúu̧ 'keerama, väänama, keerutama').

Nii häälikuliselt kui semantiliselt on balti etümoloogia laitmatu.

\section{(muna)tael : -taela 'munakollane'}

Sõna tähistab munakollast ehk -rebu saarte ja läänemurdes, mõned teated on ka läänemurdega piirnevast Risti ja Harju-Madise kihelkonnast(VMS); Mus: keedetud munal on kollane ja valge, toorel on kõik kokku tael (EKMS 2: 933 Muna). Vanemas leksikograafias on kõnealuse sõna kohta sellised teated: Göseken 1660: 182 Eyer Dotter Munna tail, A 182 Ey mit 2. Dottern kahhe Taila ka Munna; Vestring 1998 [1710-1730]: 236 Tael G la \{Der Dotter\} im Ey; Hupel 1780: 219 munna tael r. das Weisse im Ey.

Andrus Saareste (1924: 113-114) seisukoht on olnud, et (muna) tael $\sim$ taal - nii nagu eesti munakollasenimetused rebu, (muna) kollane jt, (muna) ruuge, (muna) ruske, vahanõ muna, verrev muna - on „kujundatud aine oranžkollase värvi põhjal". Munakollase värvus nimetamismotiivina on hästi tuntud nii meie sugulaskeeltes kui ka mujal. Julius Mägiste järgi (EEW 9: 3033-3034 sub tael) on kõigis läänemeresoome keeltes leviva balti laenu tael 'tuletael (Fomes fomentarius) ja sellest valmistatud süütematerjal' tähendusvälja eesti murdekeeles lisandunud eritähendus 'munakollane'. Soome etümoloogiasõnaraamatud eesti taela eritähendust ei nimeta.

Vilja Oja (2013) on kokku kogunud ja analüüsinud soome-ugri keelte, sh eesti keele munakollasenimetusi ja hakanud kahtlema seisukohas mida, tõsi küll, ei ole eespool nimetatud käsitlustes sõnaselgelt välja öeldud -, et kõnealune eesti munakollasenimetus on seotud (tule)taelaga, sest võrreldes muude nimetustega on see ,,siiski üsna ebatavaline“ (ibid.: 
286-287). Värvuses kui munakollase enim levinud nimetamismotiivis pole sellegi juhtumi puhul põhjust siiski kahelda. Kasvava, alles süütematerjaliks töötlemata tuletaela viljakeha värvuses on ohtralt nii munavalgele kui -kollasele iseloomulikke värvivarjundeid, varieerudes hallist (määrdunudvalgest) kahvatu punakaspruunini, viljakeha alapind on aga purpurse tooniga pruuni värvi (vt nt Kalamees 1966: 113).

Läänemeresoome keeltes on tuletaela värvivarjundid võib-olla andnud tõuke veel selliste eritähenduste tekkeks: vdj tagla '(keele)katt / налёт (на языке)': tagla on tšeelee pääl 'katt on keele peal' (VKS 6: 49); krjT tagla '? sammas / ? soor, suuvalge': t. (rahkam muońe) on lapšilla šuušša šyńd'yhyöh 't. (kohupiima moodi) on lastel suus vaid sündides' (KKS).

Lõpetuseks pole ehk huvituseta lisada, et värvisemantika on balti päritolu ee taela jt 'tuletael ja sellest valmistatud süütematerjal' laenualuse tänapäevaste jätkajate tähendusvälja lahutamatu osa: ld dãglas 'kirju, kirev, laikudega, laiguline (siga, seelik)' (LKŽ); lt dagls, daglaîns 'valge-mustakirju (nt siga, kana)' (ME 1: 430; EH 1: 302; LEW 1: 8586 sub dègti 'põle(ta)ma'; ALEW 1: 166-167 sub dãgas 'põlemine, tulekahju, viljalõikus'; Pokorny 1: 240-241 sub *dheg ${ }^{u} h$ - 'põle(ta)ma').

\section{Lühendid}

bltLä - läänebalti keeled; d. / d - Tartu ja Võru murre, ka lõunaeesti kirjakeel [lühend Hupeli ja Wiedemanni sõnaraamatus]; (ee)K - keskmurre; (ee)Khk Kihelkonna; (ee)Lei - Leivu; H. - Harjumaa, Harjumaa murre [lühend Hupeli sõnaraamatus]; IisR - Iisaku (rannikumurre); intr. - intransitiiv; JõeK - Jõelähtme (keskmurre); koS - sürjakomi keel; (krj)A - aunusekarjala keel; (krj)T - tverikarjala keel; ltg - latgali murdekeel; mrd - murdesõna; O - Saaremaa [lühend Wiedemanni sõnaraamatus]; P - Pärnumaa põhjaeestiline osa; $r$ - põhjaeesti murre [lühend Hupeli sõnaraamatus]; Rev - Reval [lühend Vestringi sõnaraamatus]; rl - rahvaluulekeel; (sm)I - soome keele idamurre; SW - Põhja-Eesti edelaosa [lühend Wiedemanni sõnaraamatus]

\section{Kirjandus}

Ahlquist, August 1871. De vestfinska språkens kulturord. Ett linguistiskt bidrag till Finnarnes äldre kulturhistoria. Helsingfors: Finska Litteratursällskapets tryckeri.

ALEW 1-3 = Altlitauisches etymologisches Wörterbuch, 2015. Unter der Leitung von Wolfgang Hock und der Mitarbeit von Elvira-Julia Bukevičiūtė und Christiane Schiller bearbeitet von Rainer Fecht, Anna Helene Feulner, 
Eugen Hill und Dagmar S. Wodtko. Bd. 1: A-M, Bd. 2: N-T, Bd. 3: Verzeichnisse und Indices. Hamburg: Baar.

Būga, Kazimieras 1959. Rinktiniai raštai II. Vilnius: Valstybinè politinès ir mokslinès literatūros leidykla.

Būga, Kazimieras 1961. Rinktiniai raštai III. Vilnius: Valstybinè politinės ir mokslinès literatūros leidykla.

EEW 1-12 = Julius Mägiste 2000. Estnisches etymologisches Wörtebuch 1-12. Helsinki: Finnisch-Ugrische Gesellschaft.

EH 1-2 = Jānis Endzelīns, Edīte Hauzenberga 1934-1946. Papildinājumi un labojumi K. Mülenbacha Latviešu valodas vārdnīcai I-II. Rīgā: Herausgegeben vom lettischen Kulturfonds / Grāmatu apgāds.

EKMS 1-4 = Andrus Saareste 1958-1963. Eesti keele mõisteline sõnaraamat 1-4. Stockholm: Vaba Eesti.

Gutslaff, Johannes 1648. Observationes grammaticae circa linguam Esthonicam. Dorpati Livonorum: Excudebat Johannes Vogel / Acad. Typogr.

Göseken, Heinrich 1660. Manuductio ad Linguam Oesthonicam. Anführung zur Öhstnischen Sprache, Bestehend nicht alleine in etlichen præceptis und observationibus, Sondern auch In Verdolmetschung vieler Teutschen Wörter. Reval: Adolph Simon.

Hakulinen, Lauri 1968. Suomen kielen rakenne ja kehitys. Kolmas, korjattu ja lisätty painos. Helsinki: Otava.

Helle, Anton Thor 1732. Kurtzgefaßte Anweisung Zur Ehstnischen Sprache, in welcher mitgetheilet werden I. Eine Grammatica, II. Ein Vocabvlarivm, III. Proverbia, IV. Ænigmata, V. Colloqvia. Halle: Gedruckt bey Stephan Orban.

Hupel, August Wilhelm 1780. Ehstnische Sprachlehre für beide Hauptdialekte den revalschen und den dörptschen; nebst einem vollständigen Wörterbuch. Riga, Leipzig: Johann Friedrich Hartknoch.

Jaunius, Kazimieras 1972 [1879-1903]. Kalbininko Kazimiero Jauniaus rankraštinis palikimas. Katalogas ir publikacijos. Рукописное наследие языковеда Казимераса Яунюса. Каталог и публикации. Parengé S. Skrodenis. Spec. redaktorius A. Lukošiūnas. Vilnius: Lietuvos TSR valstybinè respublikinè biblioteka.

Kaalep, Heiki-Jaan, Kadri Muischnek 2002. Eesti kirjakeele sagedussõnastik. Tartu: [Tartu Ülikool]. http://www.cl.ut.ee/ressursid/sagedused/index. php?lang=et.

Kalamees, K[uulo] 1966. Seened. Tallinn: Valgus.

Karsten, T. E. 1915. Germanisch-finnische Lehnwortstudien. Ein Beitrag zu der ältesten Sprach- und Kulturgeschichte der Germanen. (= Acta Societatis Scientiarum Fennicae XLV: 2.) Helsingfors.

KÈSK = Лыткин, В. И., Е. С. Гуляев 1970. Краткий этимологический словарь коми языка. Москва: Наука. 
Kettunen, Lauri 1938. Livisches Wörterbuch mit grammatischer Einleitung. (= Lexica Societatis Fenno-Ugricae V.) Helsinki: Suomalais-Ugrilainen Seura.

Käsi, Inge 2011. Vanapärase Võru murde sõnaraamat. Rõuge, Vastseliina, Setu. Toim. Helmi Neetar. Eesti Keele Instituut. Tallinn: Eesti Keele Sihtasutus.

Laanest, Arvo 1964. Isurid ja isuri keel. Meie lähemaid sugulaskeeli. Tallinn: [Eesti NSV Teaduste Akadeemia].

Laučiūtė 1982 = Юрате Алоизовна Лаучюте 1982. Словарь балтизмов в славянских языках. Ленинград: Наука.

LEV 1-2 = Konstantīns Karulis 1992. Latviešu etimolog̣ijas vārdnīca 1-2. Rīga: Avots.

LEW 1-2 = Ernst Fraenkel 1962-1965. Litauisches etymologisches Wörterbuch 1-2. Heidelberg: Carl Winter, Universitätsverlag, Göttingen: Vandenhoeck \& Ruprecht.

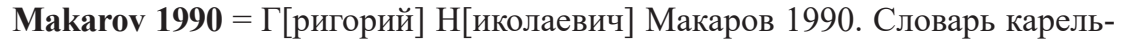
ского языка (ливвиковский диалект). Петрозаводск: Карелия.

Mažiulis, Vytautas 1988. Prūsų kalbos ètimologijos žodynas 1. Vilnius: Mokslas. ME 1-4 = K. Mīlenbacha Latviešu valodas vārdnīca 1-4, 1923-1932. Rediǵéjis, papildinājis, turpinājis J. Endzelīns. Rīgā: Herausgegeben vom lettischen Bildungsministerium / Herausgegeben vom lettischen Kulturfonds.

Mikkola, Joos. J. 1902-1903. Baltisches und Slavisches. (= Översigt af Finska Vetenskaps-Societetens Förhandlingar XLV, 4.) Helsingfors, 1-47.

Müller 1600-1606 = Külli Habicht, Valve-Liivi Kingisepp, Urve Pirso, Külli Prillop 2000. Georg Mülleri jutluste sõnastik. Toim. Jaak Peebo. (= Tartu Ülikooli eesti keele õppetooli toimetised 12.) Tartu: Tartu Ülikool.

Mägiste, Julius 1933. Mis on soomlased laenanud eesti keelest? - Eesti Kirjandus 1933/8, 368-377.

Nirvi, R. E. 1971. Inkeroismurteiden sanakirja. (= Lexica Societatis FennoUgricae XVIII.) Helsinki: Suomalais-Ugrilainen Seura.

NYS 1 = Nykysuomen sanakirja. Kuudes painos. Lyhentämätön kansanpainos, 1978. Porvoo, Helsinki, Juva: Werner Söderström Osakeyhtiö.

Oja, Vilja 2013. Наименования яичного желтка в финно-угорских языках. - Linguistica Uralica XLIX 4, 273-291.

Pokorny 1-2 = Julius Pokorny 1949-1959. Indogermanisches etymologisches Wörterbuch 1-2. Bern: A. Francke AG Verlag.

Punžina 1994 = А[лександра] В[асильевна] Пунжина 1994. Словарь карельского языка (тверские говоры). Петрозаводск: Карелия.

Raag, Raimo 1984. Ledum palustre in Baltic Finnic. - Советское финноугроведение XX/4, 258-269.

Raun, Alo 1982. Eesti keele etümoloogiline teatmik. Rooma, Toronto: Maarjamaa.

Reḳēna 1-2 = Antoṇina Reḳēna 1988. Kalupes izloksnes vārdnīca 1-2. Rīga: Latviešu valodas institūts. 
Rossihnius 1632 = Valve-Liivi Kingisepp, Külli Habicht, Külli Prillop 2002. Joachim Rossihniuse kirikumanuaalide leksika. Toim. Jaak Peebo. (= Tartu Ülikooli eesti keele õppetooli toimetised 22.) Tartu: Tartu Ülikool.

Saareste, Andrus 1924. Leksikaalseist vahekordadest eesti murretes I. Analüüs 60 kaardi ja 1 skeemiga. (= Acta et Commentationes Universitatis Dorpatensis B VI. .) Tartu: Kirjastus-Ühisuse „Postimehe” trükk.

Saareste, Andrus 1953. Länsi-Viron sanaston suhteesta suomen kieleen. (= Suomi 106/3.) Helsinki: Suomalaisen Kirjallisuuden Seura.

Saarimaa, E. A. 1916. Sananselityksiä Aleksis Kiven teoksiin. - Virittäjä 1916/3, 69-79.

Sippelgas I = Sippelgas. Essimenne jäggo. [Friedrich Reinhold Kreutzwald]. Wälja antud Maarahwa kele ja kirja koggoduse polest. Tarto liñnas: Trükkitud H. Laakmanni kirjadega ja temma kullo ning warraga 1843.

Sippelgas II = Sippelgas. Teine jagu. [V. R. Ristmets]. Tartus: H. Laakmanni kirjadega ja kuluga trükkitud 1861.

SKES 1-7 = Yrjö H. Toivonen, Erkki Itkonen, Aulis J. Joki, Reino Peltola 19741981. Suomen kielen etymologinen sanakirja 1-7. (= Lexica Societatis Fenno-Ugricae XII.) Helsinki: Suomalais-Ugrilainen Seura.

SSA 1-3 = Suomen sanojen alkuperä. Etymologinen sanakirja 1-3, 1992-2000. Päät. U.-M. Kulonen. (= Suomalaisen Kirjallisuuden Seuran toimituksia 556. Kotimaisten kielten tutkimuskeskuksen julkaisuja 62.) Helsinki: Suomalaisen Kirjallisuuden Seura, Kotimaisten kielten tutkimuskeskus.

Stahl, Heinrich 1637. Anführung zu der Estnischen Sprach, auff Wolgemeinten Rath vnd Bittliches Ersuchen, publiciret von M. Henrico Stahlen. Revall: Chr. Reusner.

Zajceva, Mullonen 1972 = Мария Ивановна Зайцева, Мария Ивановна Муллонен 1972. Словарь вепсского языка. Ленинград: Наука.

Toporov 1979 = Владимир Николаевич Топоров 1979. Прусский язык. Словарь. Е-Н. Отв. ред. В. В. Иванов. Москва: Наука.

Vaba, Lembit 1990. Die baltischen Sonderentlehnungen in den ostseefinnischen Sprachen. - Itämerensuomalaiset kielikontaktit. Itämerensuomalainen symposium 7. kansainvälisessä fenno-ugristikongressissa Debrecenissä 27.8.-1.9.1990. (= Kotimaisten kielten tutkimuskeskuksen julkaisuja 61.) Helsinki, 125-139.

Vaba, Lembit 1997. Uurimusi läti-eesti keelesuhetest. Tallinn, Tampere: Eesti Keele Instituut, Tampereen Yliopiston suomen kielen ja yleisen kielitieteen laitos.

Vaba, Lembit 2015. Sõna sisse minek. (= Eesti Teaduste Akadeemia Emakeele Seltsi toimetised 73.) Tallinn: [Eesti Teaduste Akadeemia Emakeele Selts]. 
Vestring, Salomo Heinrich 1998 [1710-1730]. Lexicon Estonico Germanicum. Tartu: Eesti Kirjandusmuuseum.

VKS 1-7 = Vadja keele sõnaraamat 1-7, 1990-2011. Toim. Elna Adler, Merle Leppik, Silja Grünberg. Tallinn: Eesti Keele Instituut.

Wiedemann, Ferdinand Johann 1973 [1893]. Estnisch-deutsches Wörterbuch. Vierter unveränderter Druck nach der von Jakob Hurt redigierten Auflage. Tallinn: Valgus.

\section{Võrgumaterjalid}

$\mathbf{E K S S}=$ Eesti keele seletav sõnaraamat. http://www.eki.ee/dict/ekss/.

EMS = Eesti murrete sõnaraamat. http://www.eki.ee/dict/ems/.

$\mathbf{E T Y}=$ Eesti etümoloogiasõnaraamat. http://www.eki.ee/dict/ety/.

$\mathbf{K K S}=$ Karjalan kielen sanakirja. http://kaino.kotus.fi/cgi-bin/kks/karjala.

LKŽ = Lietuvių kalbos žodyno (t. 1-20, 1941-2002) elektroninio varianto I leidimas 2005. http://www.lkz.lt.

Smoczyński SEJL $=$ Wojciech Smoczyński 2016. Słownik etymologiczny języka litewskiego. Współpraca redakcyjna: Michaił OsłonWydanie drugie, poprawione i znacznie rozszerzone. Na prawach rękopisu. https:// rromanes.org/pub/alii/Smoczyński W. Słownik etymologiczny języka litewskiego.pdf.

SMS $=$ Suomen murteiden sanakirja. http://kaino.kotus.fi/sms/.

VMS = Väike murdesõnastik. http://portaal.eki.ee/dict/vms . 


\title{
Alternative etymologies VII
}

\author{
LEMBIT VABA
}

The article presents new or more precise etymologies for the words kail : kailu 'white-headed cow', pendima : pendida 'to rot, decay', raidama : rajata $\sim$ raidada 'to ruin, waste', ruttama : rutata 'to hurry, hasten' ja (muna)tael : -taela 'egg yolk'.

kail : kailu 'white-headed cow' is a dialect word recorded in the Western Saaremaa parish which has a clear cognate in dialectal Finnish, where the noun kaila and its many derivatives denote primarily a skewbald or similarly colored domestic animal (cow, bull, horse). According to the data of the Finnish Dialect Dictionary, this word family is found in the southwestern (Varsinais-Suomi) and Häme dialects (western and southwestern Satakunta, northern and southwestern Häme). On the basis of the Finnish stem variants kail-o 'skewbald cow, bull or horse', kail-o-kas id., it can be claimed that the stem vowel - $u$ in Estonian kail : kailu indicates the Finnic nominal affix -o. Etymological dictionaries of Finnic languages do not address this word family. It is an eventual Baltic loan with the presumed loan base *gaila- 'white', compare to Low Prussian gaylis 'white' $<$ Latvian *gailas 'white' < 'radiant', likely Indo-European archetype *ghoilo'radiant'. This Baltic word family also includes Lithuanian gaĩlis $\sim$ gaĩle 'marsh Labrador tea'. It has previously been convincingly demonstrated that kail, the Estonian name for Ledum palustre, is also a Baltic loan.

pendima : pendida 'to rot, decay (tree, leaves), wither (turnips), grow mouldy (grain, hay), putrefy (fish, meat, corpse)' and its phonological and derivational variants are known in dialects of Northern Estonian. This Estonian verb stem has a known cognate only in dialectal Finnish, e.g. pentyä 'to rot'. Attempts to link this Estonian-Finnish stem with a similar Permic root (Udmurt pedini 'to suffocate under ice (fish), pant, gasp; to grow mouldy, fusty', Komi pedni 'to gasp, pant; to drown') fail primarily for phonological reasons.

The Estonian-Finnish verb stem pentV- is an eventual Baltic loan: Baltic *pendV-: compare to Lithuanian péndèti (péndeja péndi, péndèjo) 'to crumble, decay, rot, grow mouldy, fusty; to become weak, sickly, to dry up', išpéndèti 'to rot, decay, fester (farmhouse, tree branches, core of a growing tree); to dry and harden (meat); to become lean, thin, emaciated (due to illness or age), to grow old'.

raidama: rajata raidada 'to destroy, waste (young forest)' and the denominal adverb raidu 'to waste' from the same stem: raidu minema 'to go to waste', raidus 'being wasted' belong to the Islands and Western dialects, although they have been 
recorded in Harjumaa and elsewhere as well. The words rajama 'to waste (of grain being cut, or of children wasting bread while eating it)' and rajastama 'to waste (of grass being trampled by animals)' come from the weak-grade variant of this stem. This Estonian word family does not have plausible cognates in other Finnic languages. It is an eventual Baltic loan: Baltic *braidV-, compare to Lithuanian braidýti (braĩdo, braĩde), bráidyti 'to wade, paddle, tread on, trample', nubraidýti 'to trample, stamp on (e.g. of grain being trampled by geese and other animals); to tire from wading, splashing', apibraidýti 'to tread on, trample underfoot'. The presumed originaal meaning of this Baltic verb loan is 'to ruin or destroy something by trampling on it', from which the meaning of 'to waste, squander' has also emerged in Estonian.

ruttama : rutata 'to hurry, hasten' and the related noun rutt : rutu 'hurry, haste' are well known throughout the entire Estonian language area. ruttama, ruttu, and rutem 'faster' are among the 10,000 most frequent words in modern Estonian. Their origins can be traced to the Finnic stem *rutta-, which is the derivational base of the verb ruttama, while rutt : rutu is presumably a verbal noun with the $u$-affix $(<-o$ or ? $-u)$. This word family has cognates in all Finnic languages except Livonian and Veps. While the loan base for this word family is not (as has been suggested) Russian круmóŭ 'steep, abrupt (waterfront, curve); loud, harsh, shorttempered (of character); hard, dense, thick (e.g. a hard egg or thick porridge)', кpýmo 'abruptly, suddenly; loudly, harshly; strongly, abundantly, densely', one cannot rule out the semantic influence of these phonologically similar Russian words, including semantic loans appearing in eastern Finnish dialects and Karelian. I surmise that this Finnic stem is a Baltic loan: Baltic *kruta-, the descendants of which in modern Lithuanian include krutéti (krùta, krutéjo) 'to move, make oneself move (of a living creature or a device), to move to and fro; to show zeal, bustle about; to tremble, quiver, throb, pulsate; to loosen, break up (soil), to cultivate (soil), to scrub, clean (hide); to go, set off; to live, be located', krutas 'movement, work', krutùs 'lively, mobile, capable, hard-working, industrious', krùtinti 'to move, make smth move, force, prompt, incite to do smth; to set off, travel', krùsti (kruñta, krùto) 'to start moving, quickly start doing, embark upon smth': sukrusti pie darbo 'to get to work' and others.

(muna)tael : -taela 'egg yolk' belongs to the Islands and Western dialects, but has also been recorded in the Central dialect, which borders the Western dialect region. In Estonian etymological literature the position is taken that (muna) tael - like the other Estonian names for egg yolk: rebu, (muna) kollane jt, (muna) runge, (muna) ruske, vahanõ muna, verrev muna - is derived from the orangeyellow color of an egg yolk, and (muna)tael shares a stem with the Baltic loan tael 'tinder (Fomes fomentarius) and the combustible made from it', found in all Finnic languages, which has acquired the additional meaning of 'egg yolk' in Estonian. Finnish etymological dictionaries do not mention this additional mean- 
ing of Estonian tael. The Estonian dialect researcher Vilja Oja (2013) has begun to question this account, since tael is unusual in comparison to other names for egg yolk. However, there is no reason to doubt that coloration is the most widespread motivation in names for egg yolk, and that applies in this case as well. Growing tinder, not yet processed into a combustible, features coloration characteristic of both egg white and egg yolk, varying from gray (dirty white) to pale reddish-brown, while the base of the fruiting body is brown with a purplish tone. In Finnic languages, the coloration of tinder has evidently provided an impulse for the emergence of additional meanings. À propos, color is an inseparable part of the semantic field of Estonian tael and other modern words originating from the same loan base: Lithuanian dãglas 'variegated, multicolored, spotted, patchy (pig, skirt)' and others.

Keywords: etymology, loanwords, Estonian language, Finnic languages, Baltic languages

Lembit Vaba

phorest45@gmail.com 